\title{
Numerical Assessment of Electromagnetic Radiated Emissions from an UWB Radiators Located Inside Metallic Enclosures with Small Air-Flow Openings
}

\author{
M.M. Bait-Suwailm*, A. Boudelliou, and N. Tarhuni \\ Electrical and Computer Engineering Department, College of Engineering, Sultan Qaboos University, Muscat - Sultanate \\ of Oman.
}

Received 31 May 2016; Accepted 1 February 2018

\begin{abstract}
Shielding effectiveness of electronic devices and computing devices is essential at design stages. Devices should pass electromagnetic interference/compatibility tests for certification purposes. In this paper, we investigate the electromagnetic radiation leakage from modern personal computers and mobile electronic devices due to an ultra-wide band source of noise. Openings and slots are always unavoidable in electronic devices, for instance openings in computers for air-flow and heat dissipation. Three different designs of enclosure's covers with apertures are modeled for this purpose. The three covers cases comprise the use of rectangular arranged circular holes, hexagonal arranged circular holes, and square openings. For comparison purposes, a shielded enclosure with no openings is considered. The shielding effectiveness is numerically assessed here by capturing electric field strength that is modeled using probes located at two different distances, near- and far-away from the metallic enclosure.
\end{abstract}

Keywords: Electromagnetic interference; Metallic enclosure; Radiated emissions; Shielding effectiveness; and UWB noise.

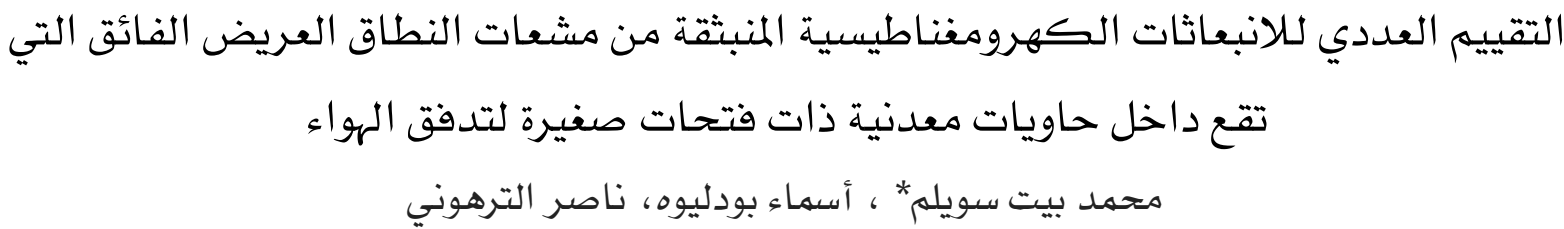

الملخص: تُعد فعالية تدريع الأجهزة الإلكترونية وأجهزة الحوسبة أمرا ضروريا جدا يوٌ مراحل التصميم. حيث يجب أن تجتاز

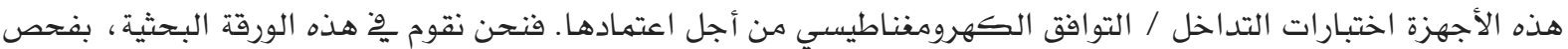
تسرب الإشعاع الكهرومغناطيسي من أجهزة الحاسوب الشخصية الحديثة والأجهزة الإلكترونية المتنقلة الناتجة عن مصدر التهر

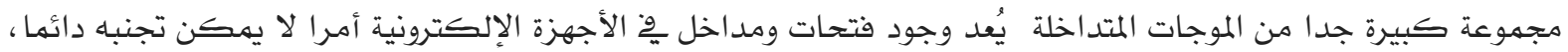
فعلى سبيل المثال، يوجد فتحات وِّ أجهزة الحاسوب من أجل تدفق الهواء وتبديد الحرارة ـ ولقد عملنا على تصميم ثلاثة نماذج

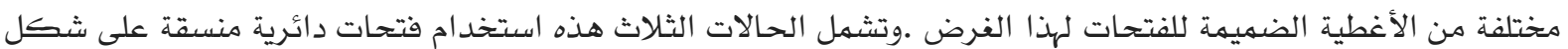
مستطيل وفتحات دائرية منسقة على شكل سداسي وفتحات مربعة.ولأغراض المقارنة، عملنا على عمل علبة محمية بدون فتحات. حيث يتم تقييم فعالية التدريع عدديا هنا من خلال نقاط شدة المجال الكهريائي التي يتم نمذجتة باستخدام مجسات تقع على مسافتين مختلفتين: القريبة والبعيدة عن العلبة المعدنية

الكلمات المفتاحية : التداخل الكهرومغناطيسي، الضميمة المعدنية، الانبعاثات المشعة، فغالية التدريع، مجموعة كبيرة جدا من الموجات المتداخلة.

* Corresponding author's e-mail: msuwailem@squ.edu.om 


\section{Introduction}

In recent years, there has been a huge demand from society in technological advancement in computers and electronic systems packaging. However, the dramatic rise in operating frequency and increased speed of electronic devices, including personal computers has indeed led to an increase in the amount of electromagnetic radiated emissions and interference (EMI) related issues. Such encountered unintentional electromagnetic radiation from devices can be attributed to several sources of noise. For instance, the rapid state switching of high-speed output drivers, which result in the simultaneous switching noise (SSN) (Ott H 1988; Senthinathan R and John L 1994). As a consequence, the disturbance from such noise may result in sever performance and integrity degradation of high-speed printed circuit boards, and even microprocessors of personal computers and mobile laptop units. Thus, it is essential to propose low-cost yet effective shielded enclosures. However, the integrity of metallic enclosures (chassis) is compromised by openings, which are needed for input/output transmission cables, air-flow and even heat dissipation. Possible radiated emissions from such perforations have to be maintained as low as possible to comply with the electromagnetic interference (EMI) radiated emissions regulations (Senthinathan $\mathrm{R}$ and John L 1994; Kubik Z and Skala J 2013).

Previous research works were carried out to investigate the effect of electromagnetic radiated emissions from high-speed printed circuit boards and enclosures with openings, for instance EMI significance in personal computers due to narrowband sources of noise (BaitSuwailam M, Ramahi O 2012; Bait-Suwailam et. al 2014; Bait-Suwailam et. al 2015; Cerri G et. al 1992; Hao J et. al 2016; Li M et. al 2000; Lin L, Ramahi O 2002; Qin J et. al 2007; Shahparnia S and Ramahi O 2004; Slyke T et. al 2008, among others). Evaluation of electromagnetic field leakage from high-speed printed circuit boards was explored in (Shahparnia $\mathrm{S}$ and Ramahi $\mathrm{O}$ 2004; Qin J et. al 2007; Bait-Suwailam M, Ramahi O 2012), while leakage from enclosures with openings was evaluated and assessed in ( $\mathrm{Li} \mathrm{M}$ et. al 2000; Lin L, Ramahi O 2002; Bait-Suwailam et. al 2014; Bait-Suwailam et. al 2015). However, significance of shielding enclosures due to unintentional Ultra-Wide Band (UWB) sources of noise needs a revisit. Recently, sudden growth in microprocessor's clock speed to several Gigahertz has been noted. The associated higherorder harmonics of the fundamental clock frequency of the microprocessor will also be a source of disturbance that can easily couple (talk) to openings with same resonance frequency. Hence, this will result in significant electromagnetic radiation from the enclosure's apertures behaving as a secondary source of radiation.

This paper presents numerical assessments of the EMI radiation leakage from airflow openings in personal computers metallic enclosures, due to UWB sources of noise in order to quantify the shielding effectiveness of such enclosures as well as higher-order harmonics of the UWB sources of noise, that may constructively add up to existing enclosure's resonances and harmonics. Hence, the system would become densely complex and can result in severe performance degradation to receivers whenever placed nearby the enclosure when placing UWB source of noise inside the enclosure. Three different cases of slots arrangement mimicking airflow openings that are found in many personal computers brands are numerically assessed using the full-wave solver of CST MW Studio (Computer Simulation Technology 2014). Numerical results are computed and compared against a reference case comprising a sealed shielded enclosure (with no openings) at both near- and far-field regions. An ultra-wideband low-profile antenna is considered here to mimic an UWB source of noise that resides inside the metallic enclosure.

\section{Modeling and Analysis}

An intentional UWB refers to a radio technology with a bandwidth exceeding 500 $\mathrm{MHz}$ or a fractional bandwidth greater than $20 \%$ of the center frequency, according to the U.S. Federal Communications Commission (FCC) (Feral Communications Commission Report). Technically, UWB devices operate by employing short duration pulses that then result in a wide transmission bandwidth. Due to the additionally posed EMI emissions limits, by the FCC, in some applications within UWB regime, it is then not surprising to expect EMI related problems when placing sensitive receivers in close proximity to an UWB source of noise. Hence, proper shielding of devices, including enclosures of personal computers and alike, is very essential. As can be seen from Fig. 1, UWB emitters must be kept below the allowable emission mask limit of $-41.3 \mathrm{dBm} / \mathrm{Hz}$.

Figure 2 shows the proposed model to investigate the EMI threats influenced on sensitive devices, that may represent high-speed printed circuit boards or memory card that are 
placed inside personal computers. For convenience, an UWB source of noise is modeled here as a circular microstrip patch antenna, where the antenna is fed by a $50 \Omega$ microstrip transmission feed line that is fed through a waveguide port as shown in Fig. 3 (Liang J et. al 2005). The antenna is printed on an FR-4 substrate with relative permittivity of 4.7 , loss tangent of 0.02 , thickness of $1.5 \mathrm{~mm}$ and board size of $L=50 \mathrm{~mm}$, and $W=42 \mathrm{~mm}$. The metallic patch has a circular shape with a radius, $R=10$ $\mathrm{mm}$. The ground plane length is $20 \mathrm{~mm}$ and the horizontal gap from the edge of the circular radiator to ground plate is $0.3 \mathrm{~mm}$. The antenna resonates quite well below $-10 \mathrm{~dB}$ over the whole UWB frequency spectrum.

Figure 4 shows the reflection coffeciont of the modeled UWB antenna, that will represent the source of noise in this study. Good antenna impedance matching can be seen, where $\left|S_{11}\right| \leq$ $-10 \mathrm{~dB}$ for the operating UWB band, covering $3.1 \mathrm{GHz}-10.6 \mathrm{GHz}$.

Due to the limited in-house laboratory resources to only narrowband measurement equipment, modeling scenarios are numerically investigated by means of CST Microwave Studio. Furtheremore, measurement validations over narrowband frequency spectrum were reported in (Bait-Suwailam M et. Al 2015).

In all studied scenarios, a perfectly matched layer, which is an absorbing boundary, is placed around the numerical computational domain that surrounds the enclosure and probes in order to avoid any reflections from the truncated space of the modeled cases. Note that the computational domain is relatively large along the y-axis (see Fig. 2), where it extends to 3.5 meters long in order to accommodate the farfield probe, which is necessary to obtain the radiated emissions from the enclosure. An adaptive mesh is considered to provide accurate measures of the electric field strength that is expected to leak out from the openings. The electric field leakage radiated out from the modeled enclosure through the aforementioned openings cases is captured in near and far fields from the enclosure surface. Note that several probes were located outside the enclosure: two at near field region $(20 \mathrm{~mm}$ and $90 \mathrm{~mm})$ and the other two are far-distant from the cover's openings (1- and 3 meters).

Among others, two of the factors that can lead to significant EM leakage in metallic enclosures are highly resonant modes of metallic enclosure (behaves as a cavity), and unavoidable slots within the enclosure's surface. The possible modes (resonant frequencies) inside an unloaded cavity with conducting boundaries (ie. metallic enclosure here) can be analytically calculated using the following well-known formula (Pozar D 2011):

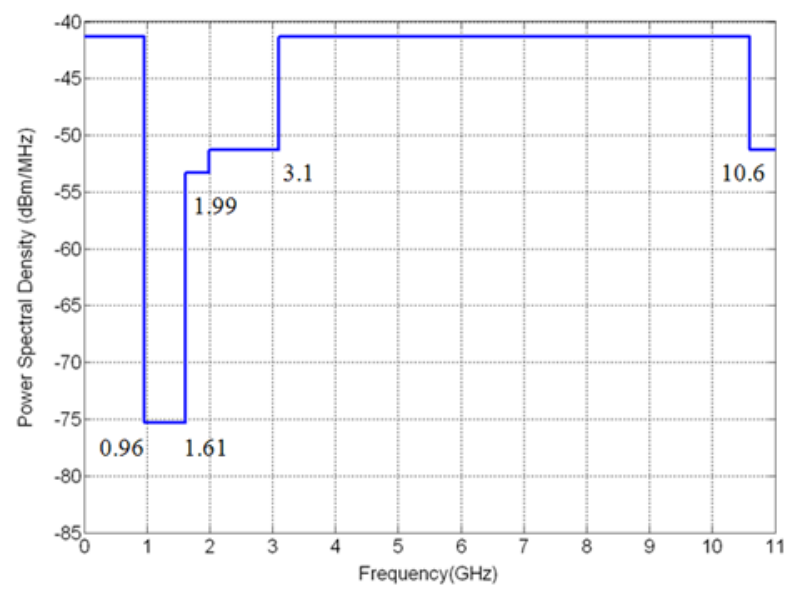

Figure 1. The FCC UWB power spectral density mask.

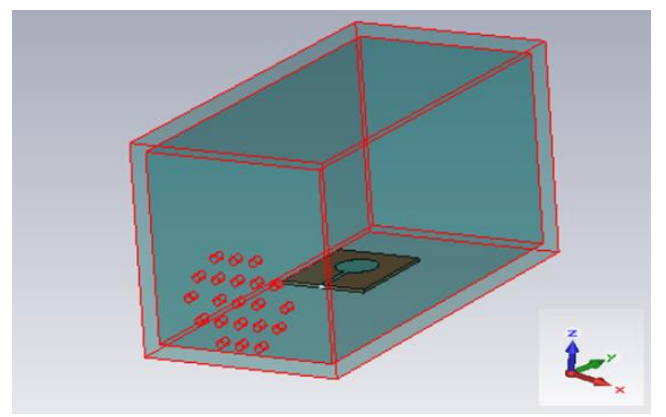

Figure 2. A $3 \mathrm{D}$ view of the modeled metallic enclosure with the UWB source of noise placed inside the enclosure. A cover case with hexagonal circular slots is also shown.

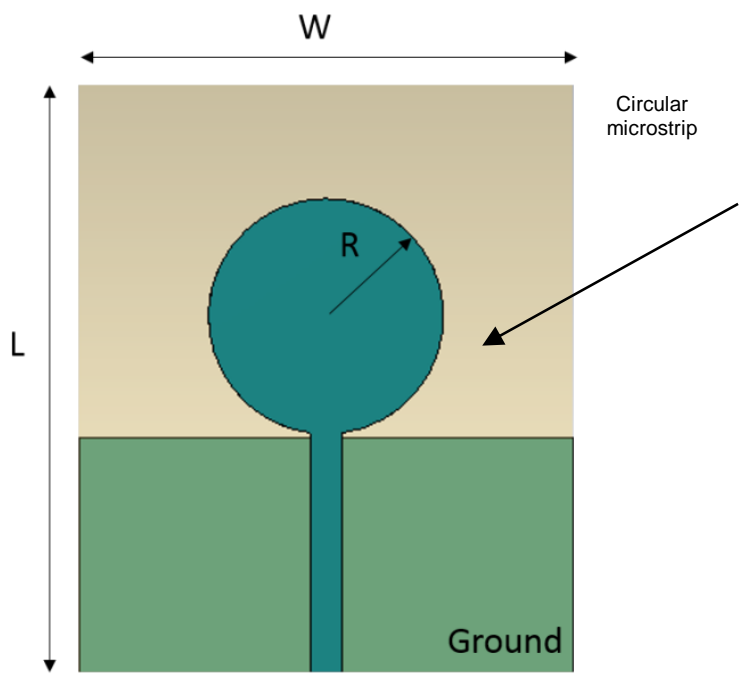

Figure 3. An UWB circular microstrip antenna modeled as a source of noise. 
$f_{\text {res }}=\frac{1}{2 \sqrt{\varepsilon \mu}} \sqrt{\left(\frac{m}{l}\right)^{2}+\left(\frac{n}{l}\right)^{2}+\left(\frac{p}{h}\right)^{2}}$,

where $\varepsilon$ is the electric permittivity, $\mu$ is the magnetic permeability, $m, n, p$ are positive integers representing the possible propagating modes inside the metallic enclosure, and $w, l$ and $h$ represent the width, length and height of the metallic enclosure along the $y, x, z$ respectively. The first 12 resonant modes (above $3.0 \mathrm{GHz}$ ) inside the metallic enclosure are displayed in Table 1. Some degenerate resonant modes are expected to exist within the metallic cavity.

In order to assess the shielding effectiveness of the metallic enclosure in presence of slots, electric field probes are used in order to monitor and quantify the amount of the electric field leakage through the openings of the enclosure. In this study, we focus on near-field and far-field strengths, specifically; probes are monitored at $20 \mathrm{~mm}$ in near-field and far-distant from the enclosure in far-field region. The shielding enclosure considered in this work has been scaled down to an acceptable size that will still maintain sufficient usage of memory through the numerical simulations runs. The enclosure width, $w=20 \mathrm{~cm}$, length, $l=10 \mathrm{~cm}$, and height, $h$ $=10 \mathrm{~cm}$, and metal thickness of $5 \mathrm{~mm}$, where $w, l$ and $h$ represent the width, length and height of the enclosure along the $y, x, z$, respectively. The enclosure is made of a perfect electric conducting material to save up memory and the UWB source of noise (antenna) was placed 25 $\mathrm{mm}$ away from the metallic ground of the enclosure along the z-direction. The antenna was excited with a discrete lumped port and the simulations were obtained using the transient analysis, time solver of CST MWS. A reference

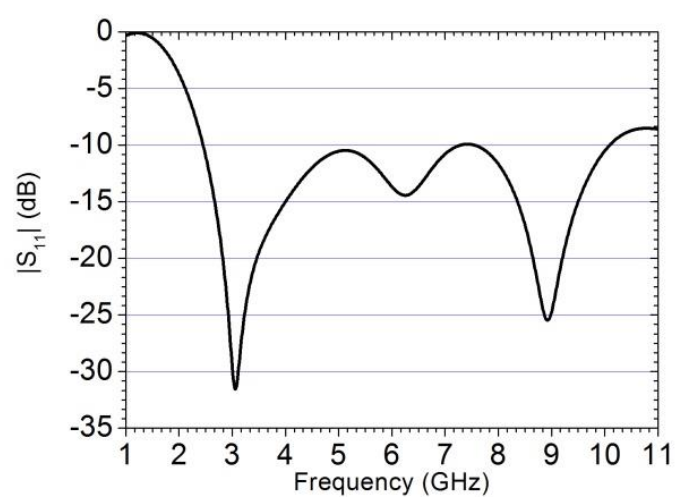

Figure 4. Simulated reflection coefficient, $\left|S_{11}\right|$, of the UWB antenna.
Table 1. Analytical resonant modes inside an unloaded metallic enclosure. Note that frequencies have been selected.

\begin{tabular}{|c|c|}
\hline $\begin{array}{c}\text { Mode } \\
\text { number }\end{array}$ & $\begin{array}{c}\text { Resonant Frequency } \\
\text { (GHz) }\end{array}$ \\
\hline 1 & 3.09 \\
\hline 2 & 3.35 \\
\hline 3 & 3.44 \\
\hline 4 & 3.44 \\
\hline 5 & 3.67 \\
\hline 6 & 3.67 \\
\hline 7 & 4.31 \\
\hline 8 & 4.50 \\
\hline 9 & 4.80 \\
\hline 10 & 4.97 \\
\hline 11 & 5.46 \\
\hline 12 & 5.61 \\
\hline
\end{tabular}

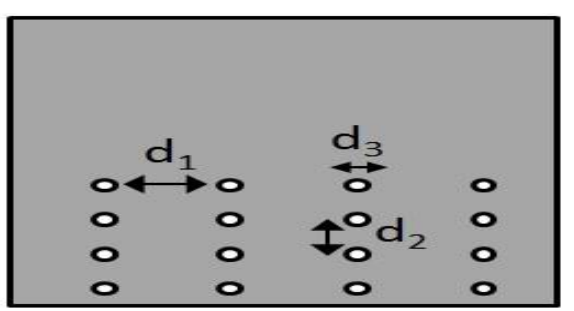

(a)

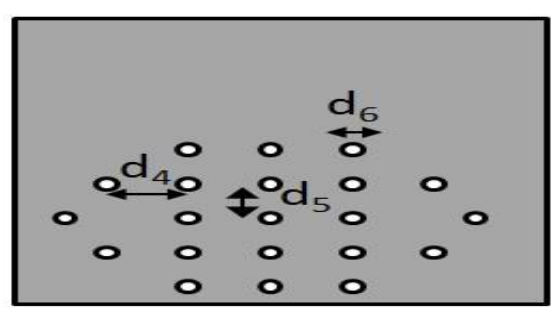

(b)

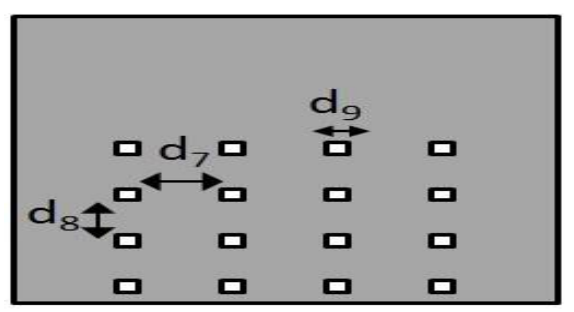

(c)

Figure 5. Side view representation of the studied enclosure with various airflow openings: (a) rectangular arranged circular holes cover $(\mathrm{d} 1=16 \mathrm{~mm}, \mathrm{~d} 2=6 \mathrm{~mm}$ and $\mathrm{d} 3=4 \mathrm{~mm}),(\mathrm{b})$ hexagonal arranged circular holes cover $(\mathrm{d} 4=6$ $\mathrm{mm}, \mathrm{d} 5=6 \mathrm{~mm}$ and $\mathrm{d} 6=4 \mathrm{~mm})$, and (c) square openings cover $(\mathrm{d} 7=16 \mathrm{~mm}, \mathrm{~d} 8=6 \mathrm{~mm}$ and $\mathrm{d} 9=4$ $\mathrm{mm})$. 
case representing a solid enclosure without any openings was considered for comparison with other proposed scenarios. As shown in Fig. 5, the suggested enclosure's openings of the four cases representing the enclosure's airflow openings are: rectangular-arranged circular holes cover (case 1), hexagonal arranged circular holes cover (case 2) and square openings cover (case 3 ).

\section{Results and Discussion}

This section presents numerical results from frequency domain analysis. In order to provide a baseline for this comparative study of enclosure's openings, the electric field leakage from a shielded enclosure with no openings is captured as shown in Fig. 6. In both near and far field regime, the magnitude of the electric field was below $-180 \mathrm{~dB}$, sufficient to quantify that there is no EMI leakage from the metallic enclosure. Field probes, that are located outside of the metallic enclosure, are used to capture the amount of field leakage through openings from the enclosure over the UWB frequency spectrum.

Next, the radiated emissions from the suggested openings in this study are numerically assessed as shown in Fig. 7. The electric field strength from opening cover of case 3 (square openings cover) provides less shielding effectiveness as compared to the other two cases. In other words, enclosure's resonances with cover of case 3 were seen high enough to reach above $-25 \mathrm{~dB}$ on average as compared to the other two cases. On the other hand, case 1 (rectangular arranged circular holes cover) provides the best shielding effectiveness of $-30 \mathrm{~dB}$ on average. Furthermore, as can be seen from Table 1 , the shaded resonances agree quite well with the resonant peaks of the captured electric field strength as shown in both Figs. 7, 8 and 9.

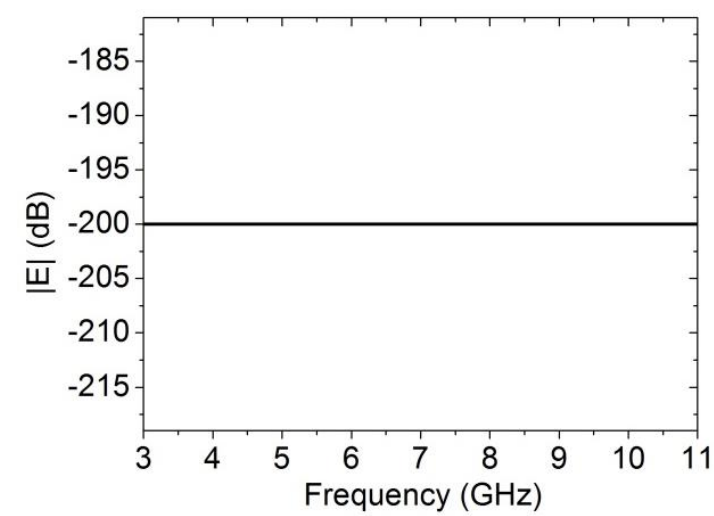

Figure 6. The electric field captured by the probes for the shielded enclosure with a solid cover (reference case).

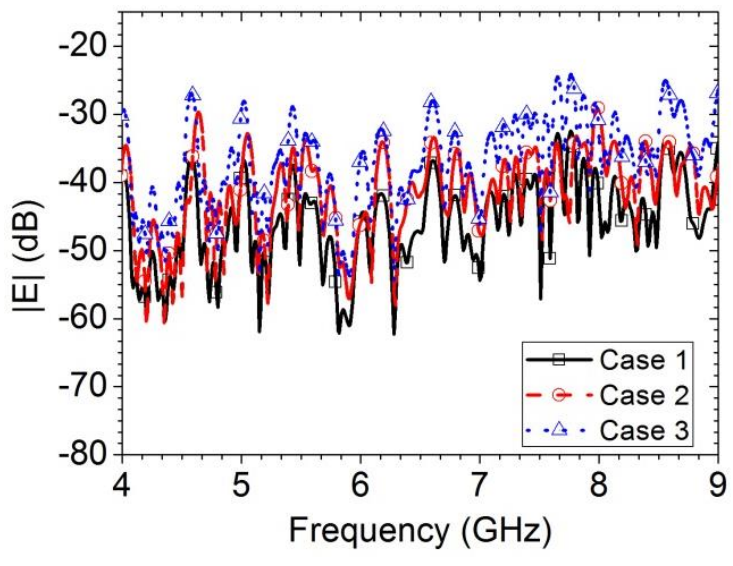

Figure 7. The electric field captured by the probes for the three cases at $20 \mathrm{~mm}$ distance away from the enclosure's opening.

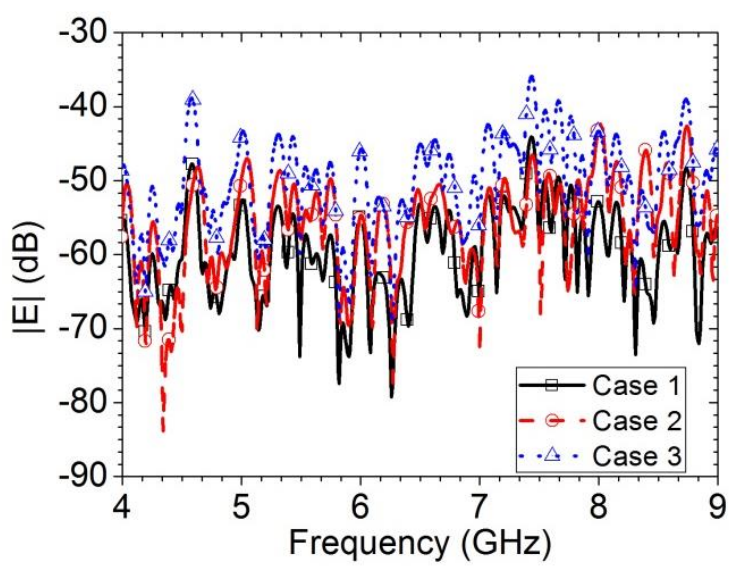

Figure 8. The electric field captured by the probes for the three cases at $90 \mathrm{~mm}$ distance away from the enclosure's opening.

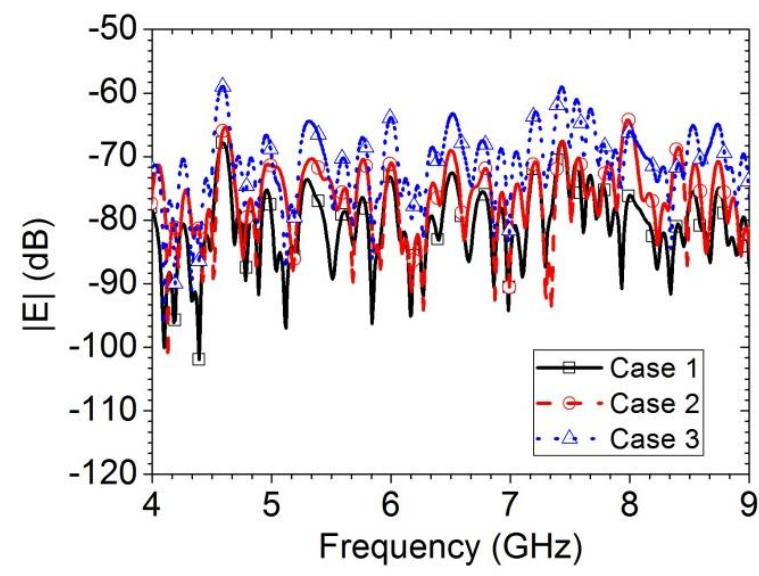

Figure 9. The electric field captured by the probes for the three cases at 1 meter distance away from the enclosure's opening. 
When placing the probe far distant away from the enclosure's openings, the EMI radiation leakage from the openings, as expected, starts to decay for all the three cases as shown in Fig. 8. The outputs are closer to each other; however, the first case of rectangular arranged circular holes cover provides the best EMI shielding effectiveness of less than $-50 \mathrm{~dB}$ on average in comparison to the other two cases at $90 \mathrm{~mm}$ as well as 1 meter (see Fig. 9) away from the enclosure's opening.

Next, it is important to study the electromagnetic field radiated emissions from the UWB source of noise that is placed inside the studied metallic enclosure, mimicking a personal computer, with various openings. In fact, radiated emission requirements for UWB systems are already set clearly in Code of Federal Regulations, telecommunications, which helps in setting up guidelines for maximal allowable electromagnetic radiated emissions from UWB source of noises (Federal Communications Commission Revision Report).

The Federal Communications Commission (FCC) regulations for radio frequency equipment defines clearly power and radiation limits in terms of electric field strength measured in volts/meter at a distance of 3 meter from the source of disturbance. In this study, to calculate the EM radiated emissions, the electromagnetic field strength at 3 meter away from the enclosure's opening is computed. In other words, broadband far-field monitors with sufficient number of discrete frequencies are evaluated, after which, radiated emissions are numerically computed using (Sanders F 2001):

$$
\begin{aligned}
& |\mathrm{E}|(\mathrm{dB} \mu \mathrm{V} / \mathrm{m})=\mathrm{P}_{\text {observed }}(\mathrm{dBm})+77.2 \mathrm{~dB} \\
& \quad+20^{*} \log _{10}(f)-\mathrm{G}_{\text {Ant. }}
\end{aligned}
$$

where $\mathrm{P}_{\text {observed }}$ is the power recorded at 3 meter away from the source in $\mathrm{dBm}, f$ is the operating frequency in $\mathrm{MHz}$, and $\mathrm{G}_{\text {Ant. }}$ is the peak gain of the antenna in $\mathrm{dB}$, while the constant $77.2 \mathrm{~dB}$ is a correction factor.

Figure 10 depicts the electric field strength that is captured in far-field, at 3 meters away from the enclosure. As can be seen from the figure, within the UWB frequency regime, 3.1 $\mathrm{GHz}-10.6 \mathrm{GHz}$, the enclosure's opening with circular holes that are arranged in rectangular fashion, case 1, shows the minimal electromagnetic radiated emission in comparison to the other two cases. It is also observed that hexagonal circular holes show better shielding performance as compared to the case of rectangular holes (case 3, see Fig. 3c), except around $8 \mathrm{GHz}$, where radiated emission was high reaching $53 \mathrm{~dB} \mu \mathrm{V} / \mathrm{m}$. Furthermore, significant radiated electromagnetic emission from case 3 is observed within the upper frequency band of the UWB regime, roughly from $5.5 \mathrm{GHz}-6.5 \mathrm{GHz}$ as well as above 10 $\mathrm{GHz} \quad \quad$ Numerical results from figure 10 correlates well with both Figs. 7, 8 and 9. Table 2 presents quantitative measures of electromagnetic radiated emissions at 3 meters distance away from the perforated enclosure for 3 selected frequencies within the UWB operating regime of the source of noise. It is observed that at $10 \mathrm{GHz}$, case 2 provides slightly better shielding performance than case 3. Overall, enclosure with cover of case 1 performs better than the other two cases. It is clear from Figure 9 that the FCC Class B EMI limit of radiated emissions is around $54 \mathrm{~dB} \mu \mathrm{V} / \mathrm{m}$, in which all

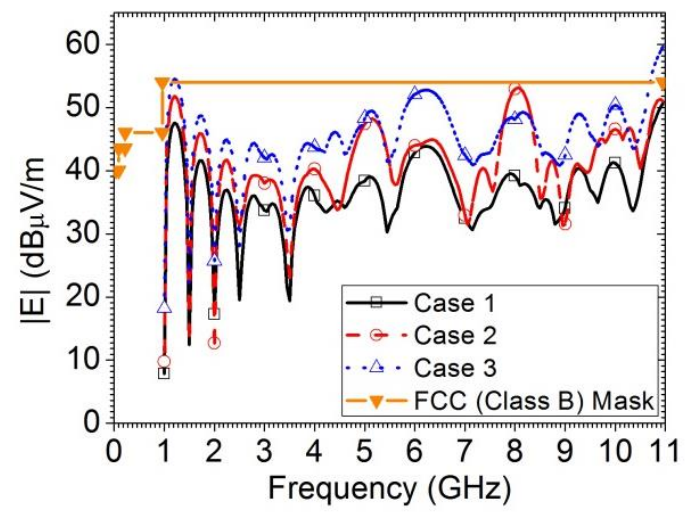

Figure 10. The electric field strength captured in far-field at 3 meters. The recommended FCC mask is also shown, where class $B$ refers to the standard applied to non-residential use of personal computers/portable laptops.

Table 2. Comparison of electromagnetic radiated emissions from the perforated metallic enclosure for the studies scenarios at an observation point placed 3 meters away from the enclosure.

\begin{tabular}{|c|c|c|}
\hline $\begin{array}{c}\text { Frequency } \\
\mathbf{4} \mathbf{~ G H z}\end{array}$ & Case type & $\begin{array}{c}\text { Radiated emission } \\
\text { strength (in } \\
\mathbf{d B} \boldsymbol{\mu} \mathbf{V} / \mathbf{m})\end{array}$ \\
\cline { 2 - 3 } & Case 1 & 35.78 \\
\cline { 2 - 3 } & Case 2 & 40.42 \\
\cline { 2 - 3 } & Case 3 & 43.54 \\
\hline \multirow{3}{*}{$\begin{array}{c}\text { Frequency }= \\
\text { 7 GHz }\end{array}$} & Case 1 & 32.20 \\
\cline { 2 - 3 } & Case 2 & 32.76 \\
\cline { 2 - 3 } & Case 3 & 42.30 \\
\hline Frequency $=$ & Case 1 & 41.16 \\
\cline { 2 - 3 } $\mathbf{1 0 ~ G H z}$ & Case 2 & 46.60 \\
\cline { 2 - 3 } & Case 3 & 50.36 \\
\hline
\end{tabular}


studied perforated enclosures had maintained their shielding strength below the mask limit, except at few discrete frequencies.

\section{Conclusion}

In this paper, a comprehensive study of the EMI effectiveness from different airflow openings scenarios due to an ultra-wide band source of noise is conducted. The amount of electromagnetic field leakage from the enclosure's opening was numerically assessed using electric field probes that monitor field strength at locations within near- and far-field region from the enclosure's opening. Three different scenarios of openings for continuous air-flow are considered. An UWB source of noise is modeled and presented here using a circular microstrip patch antenna that is located inside the enclosure.

Based on full-wave numerical assessments, results show that the rectangular arranged circular holes cover case provided better shielding effectiveness and a reduction of $-5 \mathrm{~dB}$ in the amount of electric filed strength as compared to other proposed cases.

\section{Conflict of Interest}

The authors declare no conflicts of interest.

\section{Funding}

This work is financial supported by Internal Research Grant (IG/ENG/ECED/14-01).

\section{Acknowledgment}

The authors would like to thank Sultan Qaboos University, Oman for providing the financial resources needed for this work.

\section{References}

Bait-Suwailam M, Ramahi O (2012), Ultrawideband mitigation of simultaneous switching noise and EMI reduction in highspeed PCBs using complementary split-ring resonators. IEEE Transactions on Electromagnetic Compatibility 54(2): 389- 396

Bait-Suwailam M, Alavikia B, Ramahi O (2014), Reduction of electromagnetic radiation from apertures and enclosures using electromagnetic bandgap strucutres. IEEE Transactions on Components, Packaging and Manufacturing Technology 4(5): 929-937.
Bait-Suwailam M, Al-Abri D, Teirab A, Jervase J, Nadir Z (2015), Electromagnatic Interference (EMI) Radiation from Airflow Openings in Personal Computers Shielding Enclosures: An Experemental Study. In the $8^{\text {th }}$ IEEE GCC Conference \& Exhibition 1-4.

Cerri G, De Leo R, Primiani V (1992), Theoretical and experimental evaluation of the electromagnetic radiation from apertures in shielded enclosure. IEEE Transactions on Electromagnetic Compatibility 34(4): 423-432.

Computer Simulation Technology (CST), Microwave Studio (MWS), 2014 [Online]. Available: http://www.cst.com.

Federal Communications Commission Report, FCC 02-48 [Online]. Available: https://apps.fcc.gov/edocs_public/attachm atch/FCC-02-48A1.pdf

Federal Communications Commission Revision Report (2002), Revision of Part 15 of the Commission's Rules Regarding UltraWideband Transmission Systems. ET Docket 98-153.

Hao J, Jiang L, Gong Y, and Fan J (2016), Study of the shielding effectiveness of double rectangular enclosures with apertures excited by an internal source. Progress In Electromagnetics Research M, (47): 67-76.

Kubik Z, and Skala J (2013), Influence of the cavity resonance on shielding effectiveness of perforated shielding boxes. In the Proceedings of the 8th International Conference on Compatibility and Power Electronics 260263.

Li M, Nuebel J, Drewniak J, DuBroff R, Hubing T, Van Doren T (2000), EMI from Airflow Aperture Arrays in Shielding EnclosuresExperiments, FDTD, and MoM Modeling. IEEE Transactions on Electromagnetic Compatibility 42(3): 265-275.

Liang J, Chiau C, Chen X, Parini C (2005), Study of a printed circular disc monopole antenna for UWB systems. IEEE Trans. On Antennas and Propagation 53(11): 3500-3504.

Lin L, Ramahi O (2002), Analysis and reduction of electromagnetic field leakage through loaded apertures. In the 2002 International IEEE Antennas and Propagation Society Symposium 102-105.

Ott H (1988), Noise Reduction Techniques in Electronic Systems, $2^{\text {nd }}$ Edition, John Wiley and Sons Inc.

Pozar D (2011), Microwave Engineering., $4^{\text {th }}$ edition, John Wiley \& Sons, Inc., 284-287.

Qin J, Ramahi O, Granatstein V (2007), Novel planar electromagnetic bandgap structures for mitigation of switching noise and EMI reduction in high-speed circuits. IEEE 
Transactions on Electromagnetic Compatibility 49(3): 661- 669 .

Sanders F (2001), Conversion of power measured in a circuit to incident field strength and incident power density, and corrections to measured emission spectra for non-constant aperture measurement antennas. Appendix $C$ of NTIA Report 01-383.

Senthinathan R, John L (1994), Simultaneous Switching Noise of CMOS Devices and Systems, Norwell, MA: Kluwer.
Shahparnia S, Ramahi O (2004), Electromagnetic interference (EMI) reductionfrom printed circuit boards (PCB) using electromagnetic bandgapstructures. IEEE Transactions on Electromagnetic Compatibility 46(4): 580- 587.

Slyke T, Kuhn W, Natarajan B (2008), Measuring interference from a UWB transmitter in the GPS L1 band. In the IEEE Radio and Wireless Symposium 887-890. 